discovery presents a conundrum. Loved ones of similar patients will clamour for a chance to see whether they, too, are capable of similar feats. Clinical neuroscientists should stress that no two vegetative patients are alike, and that this remarkable case may be a one-off.

Unique or not, the discovery blurs the distinction between a vegetative patient and those classed as 'minimally conscious' - showing limited or intermittent interaction with their surroundings. As the patient has reportedly improved since the study was carried out, it is entirely possible that the brain scans simply reflected early signs of her recovery. But with brain scanning of vegetative patients becoming more common (although far from routine), the medical criteria for diagnosing a vegetative condition will have to be scrutinized.

A patient is currently classed as vegetative if there are no outward signs of genuine awareness, rather than simple reflex responses to stimuli such as pain. But although this patient remained inscrutable throughout the study, her brain scans suggested she was picturing herself scampering across a tennis court, or roaming around her home. If such rich internal mental processes are seen in other outwardly vegetative patients, then clinicians should revise their opinion on whether or not these patients are really vegetative at all.

Some clinicians take issue with the use of the word 'vegetative' and the unpleasant imagery it evokes. Replacing it with the term 'outwardly unresponsive' would help to eliminate any confusion over whether internal awareness should be factored into a diagnosis. But the ultimate impact of this discovery will hinge on whether more patients are found to have this sort of inner responsiveness. Then, the issue of what constitutes consciousness in these patients - a question that transcends mere brain imaging - will come alive.

\section{Resisting terrorism}

\section{Government agencies, stakeholders and fellow researchers need to support primate researchers.}

A neuroscientist at the University of California, Los Angeles (UCLA), last month declared that he would abandon his federally funded research on non-human primates after being terrorized for years by opponents of animal research. This is only the latest of many such incidents in the United States and Europe. Yet it should serve as a wake-up call to the US research community as a whole and those who have a stake in it.

The tactics of extremist groups go beyond expressing their opinions via peaceful protest. They include intimidating scientists' families, and scaring others to the point where they are reluctant to speak out for fear of being targeted themselves. Some are not above using terror tactics - in the recent UCLA case, a bomb was left on the doorstep of a researcher's 70 -year-old neighbour. The strategy is often to single out vulnerable researchers for harassment. Neuroscientists who do basic research on primates are deemed attractive targets because of the relative ease of whipping up public sympathy for the animals and of portraying the research as having no practical benefit.

However, the problem is not specific to primate studies or basic research. There is clear evidence that extremists, emboldened by their success, are pursuing the end of all animal research. Researchers should not complacently imagine that this is someone else's problem just because their own lab does no primate research.

It is essential that scientists, scientific societies, university administrators, government and law-enforcement agencies coordinate their responses to this threat to fundamental research. Universities and scientific agencies have a responsibility to stand behind their researchers in their efforts to conduct studies that have already been stringently vetted through review both by the scientific community for its scientific value, and by animal-care committees. In the United States, the latter include veterinary surgeons as well as local-community representatives with no vested interest in the research. They are charged with ensuring ethical standards and minimizing animal discomfort.

Individual scientists are vulnerable to the enormous pressure that well-organized groups can apply and are limited in how they can respond. Universities and scientific agencies can and should exert their muscle to provide support to targeted scientists, whether it be through material support, defending the value of their research to the public on their behalf, or by working with government and lawenforcement agencies to protect them.

Scientists in Britain - no strangers to animal activism - have benefited from recent legislation amending the Serious Organized Crime Act, which defines animal extremism as terrorism. In the United States, people should familiarize themselves with (and consider supporting) similar bills, such as the Animal Enterprise Terrorism Act currently going through Congress, which would help to protect researchers from acts of intimidation and violence.

At the same time, neuroscientists who work with primates should recognize that although the value of primate research may seem so obvious as not to require explanation, it is often not recognized as such, even by other biologists.

Non-human primates are still uniquely valuable in animal research because of the similarity of their brains and many of their behaviours to ours. Non-invasive research methods in humans such as functional magnetic research imaging (fMRI) - often held up by opponents of primate research as a technology that obviates invasive procedures - can provide a complementary and more indirect view, but they do not replace the information that can be gained through more direct manipulations.

These provide the means to crack some basic questions about the neural computations, circuitry and organization that underlie human behaviour. Such information can also directly or indirectly aid research that could have practical applications. For example, the development of deep brain stimulation as a treatment of Parkinson's disease has benefited enormously not just from a primate model for the disease, but also from an understanding of the basic principles of basal-ganglia circuitry worked out through anatomy, lesion and recording studies.

The value and promise of such knowledge is clear. The researchers who pursue it need to do more to explain to the public and their colleagues why primate experiments are necessary, and to be sensitive to concerns about animal welfare. They require and deserve the coherent support of their fellow researchers and stakeholders. 